\title{
Impact van afwijkende werktijden: wat weten we vanuit de wetenschappelijke literatuur?
}

\author{
Marianne van Zwieten, Irene Houtman, John Klein Hesselink
}

\begin{abstract}
SAMENVATTING
Dit artikel geeft een overzicht van wat bekend is vanuit de wetenschap over de relatie tussen afwijkende werktijden en gezondheid en welbevinden van werknemers. De literatuur laat zien dat het werken op afwijkende werktijden samenhangt met diverse negatieve gezondheidsgevolgen. Zo is overwerk gerelateerd aan hart- en vaatziekten en is er beperkt bewijs voor een causaal verband tussen langdurig nachtwerk en borstkanker. Verder lijkt ploegendienst samen te hangen met maag-darmstoornissen. Overwerk hangt ten slotte samen met meer spier- en gewrichtsklachten, slaapproblemen en fouten maken.

In de discussie wordt ingegaan op de Arbeidstijdenwet, de toepassing van onderzoeksresultaten op het gebied van afwijkende werktijden en de nieuwe ontwikkelingen rond zelfroosteren als mogelijkheid voor werkgevers en werknemers om de nadelige invloed van afwijkende werktijden op de veiligheid, de gezondheid en het welzijn van werknemers terug te dringen.
\end{abstract}

\section{SUMMARY}

Impact of non-standard working hours: what does scientific literature tell us?

This article summarizes the current state of scientific literature on the relationship between non-standard working hours and the health and well-being of employees. The great variation in study designs and the crosssectional nature of many studies make it difficult to draw firm conclusions as to causal relations. However, literature does show a number of negative health effects of working non-standard hours. Overwork shows a relation with cardiovascular disorders, while shift work seems to be related to gastrointestinal complaints. There is some limited evidence for a causal relation between long-term night shifts and breast cancer. Long working hours show a relation with musculoskeletal complaints, disturbed sleep patterns and a greater risk of making mistakes and accidents.

There is legislation in place to protect workers from the adverse effects of non-standard working hours. This, with recommendations from the literature on sound shift rosters and new developments like 'self-rostering' are a way to diminish the negative impact of working non-standard hours.

$\begin{array}{ll}\text { AFWIJKENDE } & \begin{array}{l}\text { Dr. D.J. Klein Hesselink is onderz } \\ \text { WERKTIJDEN, }\end{array} \\ \text { GEZONDHEIDS- } & \text { Allen zijn verbonden aan TNO, Wor, Hoofddorp. } \\ \text { GEVOLGEN, } & \\ \text { LITERATUUR- } & \text { CORRESPONDENTIEADRES } \\ \text { ONDERZOEK } & \text { E-mail: irene.houtman@tno.nl. }\end{array}$

Onder normale werktijden wordt in Nederland veelal een werkweek verstaan die loopt van maandag tot en met vrijdag, waarbij overdag ongeveer acht uur wordt gewerkt. In verschillende sectoren en beroepsgroepen is het om uiteenlopende redenen noodzakelijk afwijkende werktijden te hanteren. In ziekenhuizen is het bijvoorbeeld nodig voor het waarborgen van continue zorg. Maar ook in gevangenissen en bij de politie is het vereist voor het handhaven van de orde en veiligheid. Daarnaast zijn er economische motieven om de werktijden zo in te delen dat het productieproces 24 uur per dag doorgaat, zoals in de industrie gebeurt. Naast deze motieven die vooral zijn gericht op klant en bedrijf wordt werknemers ook steeds vaker de mogelijkheid geboden zelf werktijden te kiezen en in te delen. Door deze tijdsautonomie kunnen werknemers (deels) zelf bepalen op welke momenten zij werken, waardoor bijvoorbeeld werk en privé beter op elkaar kunnen worden afgestemd.

Op de reguliere werktijden zijn tal van afwijkingen mogelijk, maar deze betreffen altijd de duur van het werk en/of het moment waarop wordt gewerkt. Bij een afwijkende duur gaat het bijvoorbeeld om overwerk waarbij er meer uren wordt gewerkt dan het contractueel afgesproken aantal, of om I 2-uursdiensten in plaats van werkdagen van acht uur. Voorbeelden van afwijkende werkmomenten zijn's avonds of 's nachts werken of in het weekend. Vaak is sprake van een combinatie van afwijkende werkduur en afwijkend werkmoment, zoals nogal eens het geval is bij overwerk maar ook bij ploegendiensten. Daarnaast is bij ploegendiensten meestal sprake van een bepaalde mate van onregelmatigheid, waarbij diensten roteren zodat vroege, late en nachtdiensten elkaar afwisselen. De snelheid en richting van rotatie kan per rooster verschillen. Naast de roosters die vrij gangbare werktijden hanteren, zijn er dus allerlei roostersystemen denkbaar die hier op de een of andere manier van afwijken. Al deze verschillende vormen van afwijkende werktijden kunnen diverse gevolgen hebben voor werknemers.

Dit artikel geeft een overzicht van wat bekend is vanuit de wetenschap over de relatie tussen afwijkende werktijden en gezondheid en welbe- 
vinden van werknemers. Hierbij is vooral uitgegaan van reviews die de relatie tussen enerzijds overwerk, lange diensten, nachtwerk en ploegendienst en anderzijds fysieke en psychische gezondheid en welbevinden in kaart hebben gebracht. De onderzoeksvraag die wordt beantwoord, is:

I Wat is er bekend over de relatie tussen afwijkende werktijden en gezondheid en welbevinden van werknemers?

In een tweede artikel van dezelfde auteurs in dit themanummer van TBV wordt beschreven in hoeverre het werken op afwijkende werktijden in Nederland voorkomt. ${ }^{\mathrm{I}}$

\section{AFWIJKENDE WERKTIJDEN \\ EN GEZONDHEID}

In een groot aantal onderzoeken is de samenhang tussen (afwijkende) werktijden en gezondheid onderzocht. Door de grote diversiteit in onderzochte roosters en diensten zijn deze studies niet altijd goed te vergelijken. Dit is vooral het geval bij onderzoek naar ploegendiensten, aangezien hierbij sprake is van veel variërende factoren (bijvoorbeeld wel of geen nachtdienst, vast of roterend rooster, rotatierichting). Maar ook bij overwerk zijn er veel aspecten waarop de onderzoeken verschillen. Zo richt het ene onderzoek zich op meer dan 8 uur per dag werken in combinatie met meer dan 40 uur werk per week, terwijl in het andere onderzoek wordt uitgegaan van meer dan 60 uur per week werken. Verder hanteren de studies veel verschillende indicatoren voor gezondheid. Door de grote variatie in onderzoeken is het doen van eenduidige uitspraken die zijn gebaseerd op voldoende bewijs, lastig. Een ander aandachtspunt is dat het voornamelijk cross-sectioneel onderzoek betreft, waarbij in de meeste gevallen niet is gecontroleerd voor mogelijke andere risicofactoren. Over causaliteit kan daarom vaak weinig worden gezegd. Verder is nauwelijks onderzoek gedaan naar interacties tussen risicofactoren. Ondanks deze beperkingen wordt in meerdere reviews wel bewijs gevonden voor een relatie tussen werktijden en gezondheid. Hierna wordt op hoofdlijnen beschreven wat hierover bekend is.

\section{Algemene gezondheid}

In verschillende onderzoeken blijkt het aantal uren werk gerelateerd aan een slechtere zelf gerapporteerde gezondheid. Zo vergroot meer dan 45 uur per week werken de waarschijnlijkheid van het rapporteren van negatieve effecten van werk op gezondheid. ${ }^{2}$ Verder rapporteert
$75 \%$ van de managers die meer dan 60 uur per week werken dat het maken van lange werkdagen de gezondheid negatief beïnvloedt, terwijl dit geldt voor slechts 2 I\% van de managers die minder dan 35 uur per week werken. ${ }^{3}$ Er zijn echter ook enkele onderzoeken die geen significante relatie vinden.

\section{Ziekten en aandoeningen}

Het werken op afwijkende werktijden wordt in verband gebracht met verschillende ziekten, aandoeningen en stoornissen. Hieronder wordt achtereenvolgens ingegaan op hart- en vaatziekten, maag-darmstoornissen, (borst)kanker en spieren gewrichtsklachten.

\section{Hart- en vaatziekten}

Hart- en vaatziekten lijken gerelateerd te zijn aan overwerk. Drie casecontrolonderzoeken in de reviews van Van der Hulst ${ }^{11}$ en Caruso $^{12}$ en een recente prospectieve cohortstudie van Virtanen et al. ${ }^{13}$ laten een positief verband zien tussen overwerk en hart- en vaatziekten, ook als wordt gecontroleerd voor een groot aantal risicofactoren. De bijna uitsluitend Japanse onderzoeken die ingaan op een hoge bloeddruk in relatie tot overwerken laten een wisselend beeld zien.

\section{Maag-darmstoornissen}

In een systematisch review van Knutsson en Bøggild ${ }^{17}$ wordt de relatie tussen ploegendiensten en maag-darmstoornissen beschreven. Dit review suggereert dat werknemers in ploegendienst een

I De grote variatie in het onderzoek naar afwijkende werktijden maakt het doen van eenduidige en voldoende onderbouwde uitspraken lastig.

I Veel onderzoek is cross-sectioneel van aard.

I Overwerk, het werken in ploegendienst en 's nachts werken hangen samen met diverse negatieve gezondheidsgevolgen.

I Het sterkste zijn de studies naar de relatie met hart- en vaatziekten en is er beperkt bewijs voor een causale relatie tussen langdurig nachtwerk en borstkanker.

I Ploegendienst hangt mogelijk samen met maag-darmstoornissen.

I Lange werkdagen lijken gerelateerd aan een toename van spier- en gewrichtsklachten.

I Lange werkdagen lijken ook gerelateerd aan slaapproblemen en het maken van fouten. 
groter risico hebben op maag-darmklachten en maagzweren. In de veelal cross-sectionele studies is echter vaak niet of niet voldoende gecontroleerd voor andere mogelijke risicofactoren zoals roken en leeftijd.

\section{Kanker}

In 2007 is door de International Agency for Research on Cancer (IARC) ploegendienst die het 24-uursritme verstoort als een mogelijke carcinogene factor geclassificeerd (Groep 2A). Een systematisch review van Kolstad et al. ${ }^{32}$ gaat in op nachtwerk en het risico op borstkanker en enkele andere vormen van kanker. Hieruit blijkt dat er beperkt bewijs is voor een causale relatie tussen nachtwerk en borstkanker, terwijl er onvoldoende bewijs is voor prostaatkanker, darmkanker en kanker in het algemeen. Drie studies in het review rapporteren een significant toegenomen risico op borstkanker voor langdurig nachtwerk voor een periode van ten minste 20 à 30 jaar. Voor kortere periodes worden vrijwel geen effecten gevonden.

\section{Spier-en gewrichtsklachten}

Studies die de relatie tussen ploegendienst en spier- en gewrichtsklachten hebben onderzocht, laten verschillende resultaten zien. Vier onderzoeken in het review van Caruso \& Waters $^{41}$ die hebben gecontroleerd voor fysieke taakeisen rapporteren geen significante verschillen tussen (niet nader gespecificeerde) ploegendiensten en dagdiensten in het risico op spier- en gewrichtsklachten. Daarnaast zijn er in het review vijf studies die zes verschillende soorten ploegendienstrotaties vergelijken met dagdiensten. De resultaten hiervan lopen uiteen. Zo wordt een verhoogd risico gevonden voor dagdiensten, ${ }^{42}$ maar ook voor roterende diensten. ${ }^{26,43}$ Ook worden gemengde resultaten gerapporteerd ${ }^{24}$ en wordt er geen significant effect gevonden. ${ }^{44} \mathrm{Al}$ deze studies richten zich overigens op werkenden in de gezondheidszorg. Zhao et al. ${ }^{3 \mathrm{I}}$ hebben ook een review uitgevoerd naar ploegendienst en spier- en gewrichtsklachten bij deze doelgroep. De enige studie die een case-controlmethode hanteert, vindt geen verband tussen ploegendienst en spier- en gewrichtsklachten.

In het review van Caruso \& Waters ${ }^{41}$ is ook gekeken naar de relatie tussen lange werkdagen en spier- en gewrichtsklachten. Acht studies waarin in een bepaalde mate is gecontroleerd voor fysieke taakeisen wijzen uit dat overwerk/lange werkdagen is gerelateerd aan een significante toename in een of meer metingen van spier- en gewrichtsklachten.

\section{Gezondheidsgerelateerd gedrag}

Het werken op afwijkende werktijden kan gevolgen hebben voor het gedrag van werknemers. Zo kan de leefstijl worden beïnvloed, waardoor bijvoorbeeld slaap-, eet- en beweegpatronen veranderen. Ook kan het zorgen voor een toename van fouten in het werk of meer ongevallen. Dit kan gevolgen hebben voor zowel werknemer en werkgever als voor de klant, patiënt of passagier. Hieronder wordt ingegaan op wat bekend is vanuit de wetenschap over werktijden en slaapgedrag, vermoeidheid, het maken van fouten en het betrokken zijn bij ongevallen.

\section{Slaapgedrag en vermoeidheid}

De voornamelijk Japanse, cross-sectionele onderzoeken naar de samenhang tussen arbeidsduur en slaapduur lijken te wijzen op een negatieve samenhang tussen het aantal gewerkte uren en het aantal uren slaap. Recentelijk is ook een longitudinaal onderzoek uitgevoerd naar de relatie tussen lange werkduur en incidentele slaapproblemen door Virtanen et al. ${ }^{45}$ op basis van de Whitehall II-studie. Hieruit blijkt dat meer dan 55 uur per week werken een voorspeller is van incidentele slaapproblemen onder werknemers die bij de nulmeting geen slaapproblemen hadden. Ook als het aantal gewerkte uren per week als continue variabele wordt meegenomen en als wordt gecorrigeerd voor een groot aantal persoonskenmerken en gezondheidsgerelateerde gedragingen blijkt het aantal gewerkte uren een voorspeller van een korte slaapduur ( $<7$ uur) en problemen bij het in slaap vallen. De effecten zijn nog wat sterker als het aantal gewerkte uren herhaaldelijk is gemeten in plaats van slechts op één moment.

Verder laten enkele Japanse onderzoeken een positief verband zien tussen het aantal gewerkte uren en vermoeidheid. Deze relatie wordt soms alleen voor bepaalde groepen gevonden.

\section{Fouten en ongevallen}

In een zeer recent systematisch review van Wagstaff \& Sigstad $\mathrm{Lie}^{54}$ is de relatie tussen ploegendienst, lange diensten en nachtdienst enerzijds en ongevallen anderzijds onderzocht. De belangrijkste bevindingen zijn dat zowel een lange werkduur als ploegendienst en nachtwerk van invloed zijn op het risico op een ongeluk; en dat een werkduur van meer dan 8 uur zorgt voor een verhoogd risico op ongelukken dat cumuleert zodat het verhoogde risico voor ongeveer I 2 uur twee keer het risico van 8 uur betreft. In een systematisch review van Zhao et al..$^{\text {ix }}$ naar ploegendienst en werkgerelateerd letsel bij werkenden in de gezondheidszorg, laten zes van de zeven 
cross-sectionele studies zien dat ploegendienst samenhangt met een verhoogd risico op blootstelling aan bloed en lichaamsvocht met een verhoogd infectierisico. Het betreft lange diensten (>8 uur), roterende diensten en nachtdiensten.

\section{CONCLUSIE EN BESCHOUWINGEN}

Naar de relatie tussen afwijkende werktijden en gezondheid en welbevinden van werknemers is veel onderzoek gedaan met een grote variatie aan onderzochte roosters en gezondheidsindicatoren. Het geboden overzicht is dan ook niet uitputtend. Het huidige overzicht laat zien dat lange werkdagen of werkweken, het werken in ploegendienst en 's nachts werken samenhangen met negatieve gezondheidsgevolgen. Zo wordt overwerk gerelateerd aan hart- en vaatziekten, suggereren recente longitudinale studies hier zelfs een causale relatie, terwijl ploegendienst samenhangt met maag-darmaandoeningen. Ook is er beperkt bewijs voor een causale relatie tussen nachtwerk en borstkanker. Verder laten onderzoeken naar ploegendienst en spier- en gewrichtsklachten een wisselend beeld zien, alhoewel lange werkdagen positief samenhangen met spier- en gewrichtsklachten.

Afwijkende werktijden lijken ook van invloed te zijn op diverse gezondheidsgerelateerde gedragingen. De slaapduur hangt bijvoorbeeld negatief samen met de werkduur. Daarnaast zijn zowel een lange werkduur als ploegendienst en nachtwerk van invloed op het risico op ongevallen. Duidelijk is dat het werken op afwijkende werktijden aandacht behoeft en dat met zorg moet worden gekeken hoe negatieve gevolgen kunnen worden beperkt tot een minimum.

Om werknemers te beschermen tegen nadelige gevolgen van werktijden zijn er wettelijke regels. In de Arbeidstijdenwet (ATW) staat hoe lang een werknemer per dag en per week mag werken en wanneer men recht heeft op pauze of rusttijd. Er zijn aparte regels voor werken in nachtdienst. Deze regels zijn er met het oog op gezondheid, veiligheid en welzijn, maar ook om werk, privé en zorgtaken te kunnen combineren. Ze gelden voor werknemers van achttien jaar en ouder. Voor kinderen onder de I6 en jongeren van I 6 en I7 jaar zijn er aparte regels. Ook staan in de ATW enkele regels voor zwangere of pas bevallen vrouwen. In het Arbeidstijdenbesluit (ATB) staan uitzonderingen en aanvullingen op de Arbeidstijdenwet. Sommige regels uit de ATW en veel van de algemene en sectorale regels van het ATB kunnen alleen worden toegepast bij collectieve regelingen. Voor meer informatie over de ATW en het ATB wordt verwezen naar Goudswaard \&
Kwantes $^{69}$ en de website van het ministerie van Sociale Zaken en Werkgelegenheid.

De regels van de Arbeidstijdenwet zijn gebaseerd op de resultaten van onderzoek. In de vele onderzoeken naar werktijden formuleren ook de onderzoekers vaak aanbevelingen voor veilige en

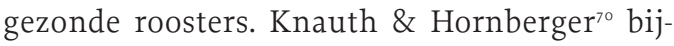
voorbeeld bevelen voor nacht-, ochtend- en avonddiensten maximaal drie dezelfde type diensten achter elkaar aan. Tevens raden ze permanent nachtwerk af. Daarnaast bevelen ze een maximum van vijf à zeven aaneengesloten werkdagen aan. De (rust)tijd tussen twee diensten moet volgens hen minimaal i I uur zijn. Weekendwerk moet zo veel mogelijk worden vermeden en de ochtenddienst moet niet te vroeg beginnen (06.30 uur is beter dan 06.00 uur bijvoorbeeld). Wagstaff \& Sigstad $\mathrm{Lie}^{54}$ geven aan dat bij een werkweek van 40 uur de kans op gezondheidsklachten en ongevallen relatief klein is. Bij meer uren per week werken neemt de kans op ongevallen en gezondheidsproblemen snel toe.

Een belangrijke nieuwe ontwikkeling om werknemers te beschermen tegen de nadelige gevolgen van nachtdiensten en lange werktijden is hen meer zeggenschap te geven over hun werktijden. Daarmee kunnen werknemers zelf hun werktijden afstemmen op hun lichamelijke en geestelijke conditie en mogelijkheden en op verantwoordelijkheden in de vrije tijd, zoals zorg voor familie of gezin. De Wet aanpassing arbeidsduur (WAA) geeft werknemers het recht om meer of minder te gaan werken, zodat ze werk en zorg beter kunnen combineren. Werkgevers mogen dit verzoek alleen afwijzen als er sprake is van een zwaarwegend bedrijfsbelang of dienstbelang, zoals onvoldoende personeel om het werk op te vangen. Momenteel wordt in de Scandinavische landen (zie het wetenschappelijke programma op www.shiftwork2or I.se) en in Nederland $^{71}$ veel onderzoek gedaan naar zelfroosteren. Werknemers kunnen daarbij hun voorkeuren voor werktijd en vrije tijd zelf inbrengen in de roosterplanning.

De tabellen en literatuurlijst van dit artikel vindt $\mathrm{u}$ als digitale pagina's $440 \mathrm{t} / \mathrm{m} 445$ op de website van TBV (www.tbv-online.nl) onder de button Themanummer 20 I I. De laatste pagina van dit artikel is 445 . 
BIJLAGE 1

Tabellen behorend bij het literatuurreview over de impact van werktijden op gezondheid en functioneren

\begin{tabular}{|c|c|c|c|}
\hline \multicolumn{4}{|c|}{$\begin{array}{l}\text { Tabel } 1 \\
\text { Zelfgerapporteerde algemene gezondheid }\end{array}$} \\
\hline Risicofactor & Gezondheidsmaat & Relatie & Referentie \\
\hline Aantal uren werk per week & $\begin{array}{l}\text { GHQ totaal } \\
\text { Somatische symptomen }\end{array}$ & $\begin{array}{l}0 \text { (univariaat) } \\
+ \text { (multivariaat) }\end{array}$ & Baldwin et al. ${ }^{4, *}$ \\
\hline $\begin{array}{l}\text { Aantal uren werk per week } \\
\text { (herhaalde metingen, drukke } \\
\text { week vs referentieweek, } \\
4 \text { metingen in } 6 \text { maanden) }\end{array}$ & $\begin{array}{l}\text { GHQ totaal } \\
\text { Ervaren stress }\end{array}$ & $\begin{array}{l}0 \text { (within subject) } \\
+ \text { (within subject) }\end{array}$ & Steptoe et al..$^{5, \star}$ \\
\hline Aantal uren werk per week & Mentale gezondheidsproblemen & 0 (multivariaat) & Tyssen et al. ${ }^{6, *}$ \\
\hline $\begin{array}{l}\text { Aantal uren werk per week } \\
(<48 ;>48)\end{array}$ & Fysieke klachten & 0 & Kirkaldy et al. ${ }^{7, \star \star}$ \\
\hline Aantal uren werk per week & Mentale gezondheid & 0 (multivariaat) & Borg \& Kristensen ${ }^{8, *}$ \\
\hline $\begin{array}{l}\text { Aantal uren werk per week } \\
(<35 ;>60)\end{array}$ & Gezondheidsperceptie & $\begin{array}{l}\text { Geeft aan dat lange werkweek } \\
\text { gezondheid negatief beïnvloedt: } \\
\text { - } 59 \% \text { van alle managers } \\
-75 \% \text { van }>60 \text { uur per week } \\
-21 \% \text { van }<35 \text { uur per week }\end{array}$ & Worrall \& Cooper $r^{3, \star \star}$ \\
\hline $\begin{array}{l}\text { Aantal uren werk per week } \\
(<35 ; 35-45 ;>45)\end{array}$ & $\begin{array}{l}\text { Negatief effect van werk op } \\
\text { psychische én fysieke gezondheid }\end{array}$ & + (multivariaat) & Ettner \& Grzywacsz ${ }^{2, *, \star *}$ \\
\hline Aantal uren werk per dag & $\begin{array}{l}\text { Fysieke belasting } \\
\text { Psychische belasting }\end{array}$ & $\begin{array}{l}+ \text { (multivariaat) } \\
+ \text { (multivariaat), sterkere relatie } \\
\text { in geval van low self-efficacy }\end{array}$ & Jex \& Bliese ${ }^{9, *}$ \\
\hline Overwerk (ja/nee) & $\begin{array}{l}\text { Gezondheidsklachten } \\
\text { (psychisch, fysiek) }\end{array}$ & $\begin{array}{l}\text { overwerk is gerelateerd aan meer } \\
\text { gezondheidsklachten }(B=0,149)\end{array}$ & Siu \& Donald ${ }^{10, * *}$ \\
\hline
\end{tabular}

\begin{tabular}{|c|c|c|c|}
\hline \multicolumn{4}{|l|}{$\begin{array}{l}\text { Tabel } 2 \\
\text { Hart- en vaatziekten }\end{array}$} \\
\hline Risicofactor & Gezondheidsmaat & Relatie & Referentie \\
\hline Aantal uren werk per dag & $\begin{array}{l}\text { Ischemische hartaandoening, } \\
\text { ziekenhuisopname in afgelopen twee } \\
\text { jaar (cases: IHD; referentiegroepen: } \\
\text { hypertensie, borderline hypertensie, } \\
\text { normale bloeddruk) }\end{array}$ & + (univariaat) & Emdad et al. ${ }^{14, \star}$ \\
\hline $\begin{array}{l}\text { Aantal uren werk per dag } \\
(<7,7-9,9-11,>11)\end{array}$ & $\begin{array}{l}\text { Acuut hartinfarct, waarbij ziekenhuisopname } \\
\text { nodig is (cases: patiënten in ziekenhuis } \\
\text { opgenomen met acuut hartinfarct; referenten: } \\
\text { gezond, gematcht op leeftijd en beroep) }\end{array}$ & $\begin{array}{l}+ \text { (multivariaat) } \\
\text { U-vormig verband: verhoogd risico op acuut } \\
\text { hartinfarct voor }<7 \text { uur per dag (OR } 2,8 \text {, } \\
\text { BI 1,5-5,3) en }>11 \text { uur per dag (OR } 2,9 \text {, } \\
\text { BI 1,4-6,3) in vergelijking met } 7-9 \text { uur per dag }\end{array}$ & $\begin{array}{l}\text { Sokejima \& } \\
\text { Kagamimori }\end{array}$ \\
\hline $\begin{array}{l}\text { Aantal uren werk per week } \\
(<41,41-60,>61) \\
\text { Vrije dagen per maand } \\
(<2,2-7,>7) \\
\text { Roterende diensten } \\
\text { (ja/nee) }\end{array}$ & $\begin{array}{l}\text { Acuut hartinfarct } \\
\text { (cases: acuut hartinfarct; controlegroep: } \\
\text { geen acuut hartinfarct, gematcht op leeftijd, } \\
\text { geslacht en woonplaats) }\end{array}$ & $\begin{array}{l}\text { Verhoogd risico voor meer dan } 61 \text { uur } \\
\text { per week werken (OR } 2,0, \mathrm{BI} 1,1-3,5) \text { in } \\
\text { vergelijking met }<41 \text { uur. Verhoogd risico voor } \\
\text { minder dan twee vrije dagen in vorige maand } \\
\text { (OR 2,9; } \mathrm{BI}, 3-6,5) \text {. Geen significante interacties } \\
\text { tussen langer werken en minder vrije dagen }\end{array}$ & Liu et al..$^{16, \star \star}$ \\
\hline Overwerk & $\begin{array}{l}\text { Aandoening van de kransslagaderen (CHD), } \\
\text { indicatoren: fatale hart- en vaatziekte, } \\
\text { niet-fataal hartinfarct en angina pectoris } \\
\text { (Whitehall II prospectieve cohortstudie) }\end{array}$ & $\begin{array}{l}\text { 3-4 uur overwerk per dag hangt samen met } \\
\text { een verhoogd risico op CHD (HR 1,60, } \\
\text { BI 1,15-2,23) in vergelijking met geen overwerk. } \\
\text { Na controle voor } 21 \text { risicofactoren: HR } 1,56 \text {, } \\
\text { BI 1,11-2,19 } \\
\text { HR (alleen voor fatale hart- en vaatziekte en } \\
\text { niet-fataal hartinfarct) is } 1,67 \text { (BI 1,02-2,76) }\end{array}$ & Virtanen et al. ${ }^{13}$ \\
\hline
\end{tabular}




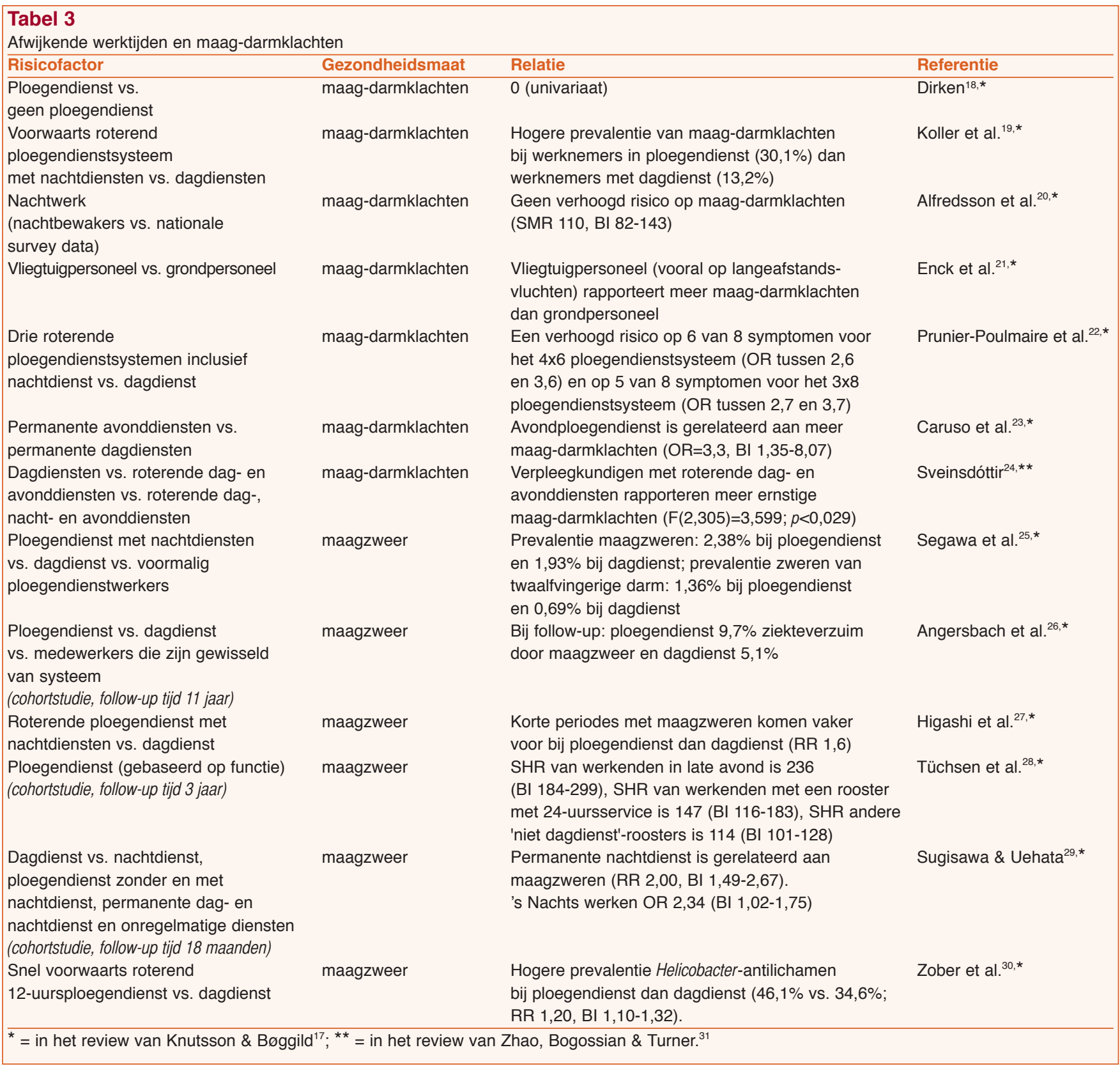




\section{Tabel 4}

Afwijkende werktijden en borstkanker

Risicofactor

Relatie

Referentie

Nachtdienst

In groep $>50$ jaar neemt de OR voor borstkanker toe met

Tynes et al. ${ }^{33,}$

(genest case-control register-linked study, cohort functieduur $(p=0,02)$.

van telegrafisten, 1961-1991)

Nachtdienst (start na 19:00, eind voor 9:00)

Adjusted OR is 1,6 (BI 1,0-2,5) voor ooit nachtdienst in 10 jaar

Davis et al. ${ }^{34, *}$

(population-based case-control study, 1992-1995) voor diagnose. OR neemt toe met uren per week nachtdienst $(p=0,03)$ en met aantal jaar met ten minste 1 nachtdienst per week $(p=0,04)$

Roterende nachtdiensten

(prospectief cohortonderzoek, verpleegkundigen,

1988-1998)

Functies waarin ten minste $60 \%$ voornamelijk

's nachts werkt (population-based register-linked

Adjusted RR neemt toe met aantal jaar dat wordt gewerkt met

roterend rooster $(p=0,02)$. Adjusted $R R$ is $1,36(B I 1,04-1,78)$

voor meer dan 30 jaar roterende dienst

OR is 1,5 (BI 1,3-1,7) voor vrouwen die ooit meer dan 6 maanden

hebben gewerkt in een functie met voornamelijk nachtdiensten in

vergelijking met vrouwen in functies waarin minder dan $40 \%$

's nachts werkt. OR is $1,7(\mathrm{BI} 1,3-1,7)$ voor vrouwen die langer dan

6 jaar werken in een functie met voornamelijk nachtdiensten

Werken in ziekenhuis

(register-linked case control study, verpleegkundigen,

1960-1982)

Roterende nachtdiensten

(prospectief cohortonderzoek, verpleegkundigen,

1989-2001)

Nachtdienst (start na 19:00 tot volgende ochtend) (population-based case control study, 1996-1997)

Functies waarin ten minste $40 \%$ roterende

diensten heeft of ten minste 1 keer per week

Adjusted OR neemt toe als aantal jaar nachtwerk toeneemt $(p=0,01)$.

Adjusted OR is 2,21 (BI 1,10-4,45) voor meer dan 30 jaar nachtwerk

in vergelijking met geen nachtwerk

Adjusted RR is 1,79 (BI 1,06-3,01) voor meer dan 20 jaar roterende nachtdiensten in vergelijking met geen nachtwerk

Adjusted OR is 0,55 (BI 0,32-0,94) voor ooit nachtdienst en 0,64

(BI 0,28-1,45) voor nachtdienst maar geen avonddienst.

Schernhammer et al ${ }^{35}$

Hansen ${ }^{36, *}$

Schernhammer et al. ${ }^{38, *}$

O'Leary et al. ${ }^{39, \star}$

Schwartzbaum et al. ${ }^{40, *}$

tussen 01.00 en 04.00 werkt (population-based

register-linked cohort study, 1971-1989)

${ }^{*}=$ in het review van Kolstad. ${ }^{32}$

\section{Tabel 5}

Afwijkende werktijden en slaapduur

\begin{tabular}{|c|c|c|c|}
\hline Risicofactor & Gezondheidsmaat & Relatie & Referentie \\
\hline $\begin{array}{l}\text { Overuren per maand } \\
(<30 ;>60)\end{array}$ & Aantal uren slaap & $\begin{array}{l}\text { - (univariaat) } \\
\text { voor groep met milde hypertensie }\end{array}$ & Hayashi et al. ${ }^{46, *}$ \\
\hline $\begin{array}{l}\text { Overuren per maand } \\
\text { (herhaalde metingen, vergelijking } \\
\text { drukke en referentie periode) }\end{array}$ & Aantal uren slaap & - (within subject) & Hayashi et al. ${ }^{46, *}$ \\
\hline $\begin{array}{l}\text { Aantal uren werk per week } \\
\text { (dichotoom, mediaansplit) }\end{array}$ & Aantal uren slaap & $\begin{array}{l}\text { - (univariaat) } \\
\text { voor groep 30-49 jaar }\end{array}$ & Sasaki et al. ${ }^{47, *}$ \\
\hline $\begin{array}{l}\text { Aantal uren werk per week } \\
\text { (drie groepen, tertilesplit: } \\
<57 ; 57,1-63,3 ;>63,3 \text { ) }\end{array}$ & Aantal uren slaap & - (univariaat) & Sasaki et al. ${ }^{48, *}$ \\
\hline $\begin{array}{l}\text { Aantal uren werk per dag } \\
(<10 ;>10) \text { (longitudinaal) }\end{array}$ & Aantal uren slaap & - (multivariaat) & Nakanishi et al. ${ }^{49, *}$ \\
\hline $\begin{array}{l}\text { Aantal uren werk per week } \\
(35-40,41-55,>55 \text { uur) }\end{array}$ & $\begin{array}{l}\text { Aantal uren slaap } \\
\text { (en andere slaapkenmerken) }\end{array}$ & $\begin{array}{l}\text { Adjusted OR voor }<7 \text { uur slaap is } \\
1,98 \text { (BI } 1,05-3,76) \text { voor }>55 \text { uur werk, } \\
3,68 \text { (BI 1,58-8,58) voor moeilijk in slaap vallen }\end{array}$ & Virtanen et al. ${ }^{45}$ \\
\hline $\begin{array}{l}\text { Overuren per maand } \\
(0-59 ; 60-79 ;>80)\end{array}$ & $\begin{array}{l}\text { Slaapduur doordeweekse dagen } \\
\text { Slaapschuld doordeweekse dagen }\end{array}$ & $\begin{array}{l}- \text { (multivariaat) } \\
+ \text { (multivariaat) }\end{array}$ & Kageyama et al. ${ }^{50, *}$ \\
\hline $\begin{array}{l}\text { Overuren per maand } \\
(<20,20-59,>60)\end{array}$ & $\begin{array}{l}\text { Slaapduur doordeweekse dagen } \\
\text { Slaapduur voor vakantiedagen }\end{array}$ & $\begin{array}{l}0 \text { (univariaat) } \\
+ \text { (univariaat) }\end{array}$ & Kageyama et al. ${ }^{51, \star}$ \\
\hline
\end{tabular}

\section{Tabel 6}

Afwijkende werktijden en vermoeidheid

\begin{tabular}{|c|c|c|c|}
\hline Risicofactor & Gezondheidsmaat & Relatie & Referentie \\
\hline Overuren per maand & Vermoeidheid voor werk & +(univariaat) & Hayashi et al. ${ }^{46, *}$ \\
\hline$(<30 ;>60)$ & Vermoeidheid na werk & + (univariaat)voor groep met milde hypertensie & \\
\hline $\begin{array}{l}\text { Overuren per maand } \\
\text { (herhaalde metingen) }\end{array}$ & Vermoeidheid & + (within subject) & Hayashi et al. ${ }^{46, *}$ \\
\hline $\begin{array}{l}\text { Aantal uren werk per week } \\
\text { (dichotoom, mediaansplit) }\end{array}$ & $\begin{array}{l}\text { Moeite met concentratie } \\
\text { Dufheid en lusteloosheid }\end{array}$ & $\begin{array}{l}\text { + (univariaat) voor werk } \\
+ \text { (univariaat) voor en na werk }\end{array}$ & Iwasaki et al. ${ }^{52, *}$ \\
\hline $\begin{array}{l}\text { Aantal uren werk per week } \\
\text { (dichotoom, mediaansplit) }\end{array}$ & $\begin{array}{l}\text { Moeite met concentratie } \\
\text { Dufheid en lusteloosheid }\end{array}$ & $\begin{array}{l}\text { + (univariaat) ('s morgens + 's middags, } 40-49 \text { jaar) } \\
\text { + (univariaat) ('s morgens, 30-39 jaar) }\end{array}$ & Sasaki et al. ${ }^{47, *}$ \\
\hline $\begin{array}{l}\text { Aantal uren werk per week } \\
\text { (drie groepen, tertilesplit: } \\
<57 ; 57,1-63,3 ;>63,3 \text { ) }\end{array}$ & $\begin{array}{l}\text { Moeite met concentratie } \\
\text { Dufheid en lusteloosheid }\end{array}$ & $\begin{array}{l}0 \text { (univariaat) } \\
0 \text { (univariaat) }\end{array}$ & Sasaki et al. ${ }^{48, *}$ \\
\hline Overuren per week & Vermoeidheid & + (multivariaat) & Proctor et al. ${ }^{53, \star}$ \\
\hline
\end{tabular}




\begin{tabular}{|c|c|c|c|}
\hline Risicofactor & Veiligheidsmaat & Relatie & Referentie \\
\hline $\begin{array}{l}\text { Middag-, nacht- en roterende } \\
\text { diensten vs. dagdiensten } \\
\text { (voedselbereidingsindustrie) }\end{array}$ & $\begin{array}{l}\text { Percentage } \\
\text { letselongevallen }\end{array}$ & $\begin{array}{l}\text { Significant hogere frequentie van letselongevallen bij } \\
\text { werknemers met een roterende dienst dan met een } \\
\text { dagdienst }\end{array}$ & Smith \& Colligan ${ }^{55, *}$ \\
\hline $\begin{array}{l}\text { Roterende ploegendienst vs. } \\
\text { dag-/avondwerk; nachtwerk vs. } \\
\text { dag-/avondwerk (verpleegkundigen) }\end{array}$ & Ongevallen & $\begin{array}{l}\text { Verpleegkundigen met een roterende dienst hebben } \\
\text { een OR van } 1,97 \text { (BI 1,07-3,63) voor rapporteren van } \\
\text { een ongeval of fout en een OR van } 2,47 \text { (BI 1,56-3,89) } \\
\text { voor bijna-ongelukken in vergelijking met } \\
\text { dag-/avond werkenden. Voor nachtwerkers is de OR } \\
\text { voor bijna auto-ongelukken } 1,92 \text { (BI 1,05-3,52) }\end{array}$ & Gold et al. ${ }^{56, *}$ \\
\hline $\begin{array}{l}\text { Aantal uren werk, aanvangstijd } \\
\text { (werknemerspopulatie, geregistreerde } \\
\text { ongelukken) }\end{array}$ & Ongevallen & $\begin{array}{l}\text { De resultaten suggereren exponentieel verhoogd } \\
\text { ongevalsrisico na } 9 \text { uur werk, vooral als aanvangstijd } \\
\text { afwijkt van die van normale werkdag. Moment van de } \\
\text { dag (bijv. nachtdienst) had geen duidelijk effect op } \\
\text { ongevalsrisico }\end{array}$ & Hänecke et al. ${ }^{57, *}$ \\
\hline $\begin{array}{l}\text { Aantal uren (nacht)werk } \\
\text { (anesthesisten: specialisten en trai- } \\
\text { nees) }\end{array}$ & $\begin{array}{l}\text { Vermoeidheidsgerelateerde } \\
\text { fouten }\end{array}$ & $\begin{array}{l}\text { Voor specialisten wordt samenhang gevonden tussen } \\
\text { aantal nachten met werkgerelateerde slaapverstoring } \\
\text { in de laatste } 14 \text { dagen en de waarschijnlijkheid een } \\
\text { fout te rapporteren (RR } 1,25 ; \mathrm{BI} 1,06-1,49)\end{array}$ & Gander et al. ${ }^{58, \star}$ \\
\hline $\begin{array}{l}\text { Traditioneel rooster met lange } \\
\text { diensten vs. interventierooster zon- } \\
\text { der lange diensten } \\
\text { (prospectieve, gerandomiseerde cross- } \\
\text { overstudie) (intensive care) }\end{array}$ & $\begin{array}{l}\text { Aantal serieuze } \\
\text { medische fouten door } \\
\text { stagiaires per } 1000 \\
\text { 'patiëntendagen' }\end{array}$ & $\begin{array}{l}\text { Stagiaires maakten } 35,9 \% \text { meer ernstige medische } \\
\text { fouten en } 20,8 \% \text { meer ernstige medicatiefouten tij- } \\
\text { dens een traditioneel rooster dan tijdens een inter- } \\
\text { ventierooster. Het totale aantal serieuze fouten was } \\
22 \% \text { hoger tijdens het traditionele rooster }\end{array}$ & Landrigan et al. ${ }^{59, *}$ \\
\hline $\begin{array}{l}\text { Duur van verschillende ploegen- } \\
\text { dienstroosters inclusief overwerk } \\
\text { vs. roosters zonder overwerk } \\
\text { (verpleegkundigen) }\end{array}$ & Fouten & $\begin{array}{l}\text { RR voor maken van fouten is } 1,85 \text { voor werkduur tus- } \\
\text { sen } 8,5-12,5 \text { uur en } 3,29 \text { voor een werkduur }>12,5 \text { uur. } \\
\text { OR voor maken van fouten is } 1,96 \text { voor }>40 \text { uur per } \\
\text { week werken en } 1,92 \text { voor }>50 \text { uur per week werken }\end{array}$ & Rogers et al. ${ }^{60, *}$ \\
\hline $\begin{array}{l}\text { Ploegendienst en preventief sla- } \\
\text { pen vs. niet preventief slapen } \\
\text { (retrospectieve en prospectieve cohort- } \\
\text { studie) (verkeerspolitie) }\end{array}$ & $\begin{array}{l}\text { Auto-ongelukken } \\
\text { tijdens werk }\end{array}$ & $\begin{array}{l}\text { Een afname van ongelukken onder chauffeurs die } \\
\text { preventief sliepen voor de nachtdienst (afname van } \\
38 \% \text { (SD } 8 \% \text { ) in de retrospectieve groep en } 48 \% \text { (SD } \\
19 \% \text { ) in de prospectieve groep }\end{array}$ & Garbarino et al..$^{61, *}$ \\
\hline $\begin{array}{l}\text { Lange diensten (meer dan } 4 \text { uur } \\
\text { overwerk) vs. normale diensten } \\
\text { (prospectieve cohortstudie) (stagiaires) }\end{array}$ & $\begin{array}{l}\text { Auto-ongelukken tijdens } \\
\text { woon-werkverkeer } \\
\text { In slaap vallen }\end{array}$ & $\begin{array}{l}\text { OR voor auto-ongelukken is } 2,3(1,6-3,3) \text { voor woon- } \\
\text { werkverkeer na lange dienst. OR voor in slaap vallen } \\
\text { tijdens rijden is } 2,39(\mathrm{BI} 2,31-2,44) \text { voor maanden } \\
\text { met > vijf lange diensten. OR voor in slaap vallen in } \\
\text { de file is } 3,69(3,60-3,77) \text { voor maanden met > vijf } \\
\text { lange diensten }\end{array}$ & Barger et al. ${ }^{62, *}$ \\
\hline $\begin{array}{l}\text { Verschillende werkroosters en } \\
\text { werktijden in de productie vs. } 40 \\
\text { uur per week of } 7-8 \text { uur per dag } \\
\text { (cohortstudie) }\end{array}$ & $\begin{array}{l}\text { Ernstige werkgerelateerde } \\
\text { ongelukken }\end{array}$ & $\begin{array}{l}\text { In bouwsector hebben werkenden die > } 8 \text { uur werken } \\
\text { een hoger \% letselongevallen dan degenen die } 7-8 \\
\text { uur werken (OR 1,57, BI 1,56-1,58). In gehele pro- } \\
\text { ductiebranche is OR } 1,98(\mathrm{BI} 1,88-2,05) \text { voor }>50 \text { uur } \\
\text { werk per week en 1,21 (BI 1,20-1,21) voor ploegen- } \\
\text { dienst }\end{array}$ & Dong et al. ${ }^{63, *}$ \\
\hline $\begin{array}{l}\text { Overwerk en langere diensten vs. } \\
\text { geen overwerk (cohortstudie) }\end{array}$ & $\begin{array}{l}\text { Werkgerelateerde } \\
\text { ongelukken/ziekten }\end{array}$ & $\begin{array}{l}\text { Adjusted HR is } 1,37 \text { (BI 1,16-1,59) voor werkdagen } \\
\geq 12 \text { uur }\end{array}$ & Dembe et al. ${ }^{64, *}$ \\
\hline $\begin{array}{l}\text { Nacht- en avonddiensten vs. dag- } \\
\text { diensten (cohortstudie) }\end{array}$ & $\begin{array}{l}\text { Werkgerelateerde } \\
\text { ongelukken }\end{array}$ & $\begin{array}{l}\text { Adjusted } \mathrm{HR} \text { is } 1,43(\mathrm{BI} 1,26-1,62) \text { voor avonddien- } \\
\text { sten, } 1,36(\mathrm{BI} 1,17-1,58) \text { voor roterende diensten en } \\
1,30(\mathrm{BI} 1,12-1,52) \text { voor nachtdiensten }\end{array}$ & Dembe et al. ${ }^{65, *}$ \\
\hline $\begin{array}{l}\text { Aantal uren slaap voor incident vs. } \\
\text { gemiddelde slaapduur } \\
\text { (vrachtwagenchauffeurs) }\end{array}$ & Ongelukken & $\begin{array}{l}\text { Bestuurders hadden significant kortere slaapduur in } \\
\text { periode voor een ongeluk in vergelijking met hun } \\
\text { gemiddelde slaapduur }\end{array}$ & Hanowski et al. ${ }^{66, *}$ \\
\hline $\begin{array}{l}\text { Roterende ploegendienst met } \\
\text { nachtdiensten vs. werken overdag. } \\
\text { Permanente nachtdiensten vs. } \\
\text { dagdiensten. } \\
>40 \text { uur vs. }<40 \text { uur }\end{array}$ & $\begin{array}{l}\text { Werkgerelateerde } \\
\text { ongelukken }\end{array}$ & $\begin{array}{l}\text { Adjusted RR is } 1,89 \text { (BI 1,49-2,41) voor roterende } \\
\text { ploegendienst met nachtdienst in vergelijking met } \\
\text { werken overdag (geen ploegendienst). Adjusted RR } \\
\text { is } 1,75 \text { (BI 1,17-2,61) voor roterende ploegendienst } \\
\text { zonder nachtdienst. Adjusted RR is } 1,32 \text { (BI 1,12- } \\
1,55 \text { ) voor }>40 \text { uur werken }\end{array}$ & Fransen et al. ${ }^{67, \star}$ \\
\hline $\begin{array}{l}\text { Aantal gewerkte uren voor dienst } \\
\text { met letsel vs. aantal gewerkte uren } \\
\text { voor dienst zonder letsel } \\
\text { (case-crossoverstudie, industrie) }\end{array}$ & Risico op letsel & $\begin{array}{l}\mathrm{HR} \text { voor letsel is } 1,88(\mathrm{BI} 1,16-3,05) \text { voor }>64 \text { uur } \\
\text { werk in } 7 \text { dagen in vergelijking met }<40 \text { uur werk }\end{array}$ & Vegso et al. ${ }^{68}$ \\
\hline
\end{tabular}


I. Zwieten M van, Klein Hesselink J, Houtman I. Impact en omvang van afwijkende werktijden in Nederland. Tijdschr Bedrijfs Verzekeringsgeneeskd 20I I, I9: 473477.

2. Ettner SL, Grzywacs JG. Workers' perceptions of how jobs affect health: a social ecological perspective. J Occup Health Psychol 200I; 6: IOI-I I3.

3. Worrall L, Cooper CL. Working patterns and working hours: their impact on UK managers. Leadersh Organ Dev J I 999; 2O(I): 6-IO.

4. Baldwin PJ, Dodd M, Wrate RW. Young doctors' health: I. How do working conditions affect attitudes, health and performance? Soc Sci Med I997; 45: 35-40.

5. Steptoe A, Wardle J, Lipsey Z, et al. A longitudinal study of workload and variations in Long workhours and health psychological well-being, cortisol, smoking, and alcohol consumption. Ann Behav Med I998; 2O(2): 84-9I.

6. Tyssen R, Vaglum P, Grønvold NT, Ekeberg $\emptyset$. The impact of job stress and working conditions on mental health problems among junior hours officers: a nationwide Norwegian prospective cohort study. Med Educ 2000; 34: 374-384.

7. Kirkcaldy BD, Levine R, Shephard RJ. The impact of working hours on physical and psychological health of German managers. Eur Rev Appl Psychol 2000; 50(4): 443-449.

8. Borg V, Kristensen TS. Psychosocial work environment and mental health among travelling salespeople. Work Stress I999; I3: I32-I43.

9. Jex SM, Bliese PD. Efficacy beliefs as a moderator of the impact of work-related stressors: a multilevel study. J Appl Psychol I999; 84: 349-36r.

Io. Siu O-L, Donald I. Psychosocial factors at work and workers' health in Hong Kong: an exploratory study. Bull Hong Kong Psychol Soc 1995; 34/35: 30-56.

I I. Hulst M van der. Long work hours and health. Scand J Work Environ Health 2003; 29(3): I 7 I-I88.

I2. Caruso CC, Hitchcock EM, Dick RB, et al. Overtime and extended work shifts: recent findings on illnesses, injuries, and health behaviors. (DHHS (NIOSH) Publ. No. 2004-I43). Cincinnati OH: Department of Health and Human Services, Public Health Service, Centers for Disease Control and Prevention, National Institute for Occupational Safety and Health, 2004.

I3. Virtanen M, Ferrie JE, Singh-Manoux A, et al. Overtime work and incident coronary heart disease: the Whitehall II prospective cohort study. Eur Heart J 2010; 3I(I4): I737-I 744 .

I4. Emdad R, Belkic K, Theorell T, Cizinsky S. What prevents professional drivers from following physicians' cardiologic advice? Psychother Psychosom 1998; 67: 226-240.

I5. Sokejima S, Kagamimori S. Working hours as a risk factor for acute myocardial infarction in Japan: casecontrol study. Br Med J 1998; 317: 775-780.

r6. Liu Y, Tanaka H, The Fukuoka Heart Study Group. Overtime work, insufficient sleep, and risk of nonfatal acute myocardial infarction in Japanese men. Occup Environ Med 2002; 59(7): 447-45I.

I7. Knutsson A, Bøggild H. Gastrointestinal disorders among shift workers. Scand J Work Environ Health 2010; 36(2): 85-95.

I8. Dirken JM. Industrial shift work: decrease in wellbeing and specific effects. Ergonomics I 966; 9: I I 5-I 24.

I9. Koller M. Health risks related to shift work. Int Arch Occup Environ Health I983; 53: 59-75.
20. Alfredsson L, Åkerstedt T, Mattsson M, Wilborg B. Selfreported health and well-being amongst night security guards: a comparison with the working population. Ergonomics I991; 343: 525-530.

2I. Enck P, Müller-Sacks E, Holtmann G, Wegmann H. Gastrointestinal problems in airline crew members. Z Gastroenterol I995; 33: 5I3-5I6.

22. Prunier-Poulmaire S, Gadbois C, Volkoff S. Combined effects of shift systems and work requirements on customs officers. Scand J Work Environ Health I998; 24 suppl 3: I34-I 40.

23. Caruso CC, Lusk SL, Gillespie BW. Relationship of work schedules to gastrointestinal diagnoses, symptoms, and medication use in auto factory workers. Am J Ind Med 2004; 46: 586-598.

24. Sveinsdóttir H. Self-assessed quality of sleep, occupational health, working environment, illness experience and job satisfaction of female nurses working different combination of shifts. Scand J Caring Sci 2006; 20(3): 229-237.

25. Segawa K, Nakazawa S, Tsukamoto Y, et al. Peptic ulcer is prevalent among shift workers. Dig Dis Sci 1987; 32: 449-453.

26. Angersbach D, Knauth P, Loskant H, et al. A retrospective cohort study comparing complaints and disease in day and shift workers. Int Arch Occup Environ Health I980; 45: I27-I40.

27. Higashi T, Sakurai H, Satoh T, Toyama T. Absenteeism of shift and day workers with special reference to peptic ulcer. Asia Pac J Public Health I988; 2: I I 2-I I 9.

28. Tüchsen F, Jeppesen HJ, Back E. Employment status, non-daytime work and gastric ulcer in men. Int J Epidemiol I994; 23: 365-370.

29. Sugisawa A, Uehata T. Onset of peptic ulcer and its relation to work-related factors and life events: a prospective study. J Occup Health I998; 40: 22-3I.

30. Zober A, Schilling D, Ott MG, et al. Helicobacter pylori infection: prevalence and clinical relevance in a large company. J Occup Environ Med I998; 40: 586-594.

3I. Zhao I, Bogossian F, Turner C. Shift work and work related injuries among health care workers: A systematic review. Austral J Adv Nurs 20I0; 27(3).

32. Kolstad HA. Nightshift work and risk of breast cancer and other cancers - a critical review of the epidemiologic evidence. Scand J Work Environ Health 2008; 34(I): 5-22.

33. Tynes T, Hannevik M, Andersen A, et al. Incidence of breast cancer in Norwegian female radio and telegraph operators. Cancer Causes Control I996; 7: 197204.

34. Davis S, Mirick DK, Stevens RG. Night shift work, light at night, and risk of breast cancer. J Natl Cancer Inst 200I; 93: I557-I562.

35. Schernhammer ES, Laden F, Speizer FE, et al. Rotating night shifts and risk of breast cancer in women participating in the nurses' health study. J Natl Cancer Inst 200I; 93: I563-I568.

36. Hansen J. Increased breast cancer risk among women who work predominantly at night. Epidemiology 200I; I 2: 74-77.

37. Lie JA, Roessink J, Kjaerheim K. Breast cancer and night work among Norwegian nurses. Cancer Causes Control 2006; I7: 39-44.

38. Schernhammer ES, Kroenke CH, Laden F, Hankinson SE. Night work and risk of breast cancer. Epidemiology 2006; I7: I08-III.

39. O'Leary ES, Schoenfeld ER, Stevens RG, et al. Shift 
work, light at night, and breast cancer on Long Island, New York. Am J Epidemiol 2006; I64: 358-366.

40. Schwartzbaum J, Ahlbom A, Feychting M. Cohort study of cancer risk among male and female shift workers. Scand J Work Environ Health 2007; 33(5): 336-343.

4I. Caruso CC, Waters TR. A review of work schedule issues and musculoskeletal disorders with an emphasis on the healthcare sector. Ind Health 2008; 46(6): 523-534.

42. Myers D, Silverstein B, Nelson NA. Predictors of shoulder and back injuries in nursing home workers: a prospective study. Am J Ind Med 2002; 41: 466-476.

43. Ottmann W, Karvonen MJ, Schmidt KH, et al. Subjective health status of day and shift-working policemen. Ergonomics I989; 32: 847-854.

44. Parkes KR. Shiftwork, job type, and the work environment as joint predictors of health-related outcomes. J Occup Health Psychol I 999; 4: 256-268.

45. Virtanen M, Ferrie JE, Gimeno D, et al. Long working hours and sleep disturbances: the Whitehall II prospective cohort study. Sleep 2009; 32(6): 737-745.

46. Hayashi T, Kobayashi Y, Yamaoka K, Yano E. Effect of overtime work on 24-hour ambulatory blood pressure. J Occup Environ Med I996; 38: I007-Ior I.

47. Sasaki T, Iwasaki K, Oka T, Hisanaga N. Association of working hours with biological indices related to the cardiovascular system among engineers in a manufacturing company. Ind Health I999; 37: 457-463.

48. Sasaki T, Iwasaki K, Oka T, et al. Effect of working hours on cardiovascular-autonomic nervous functions in engineers in an electronics manufacturing company. Ind Health I 999; 37: 55-6I.

49. Nakanishi N, Nakamura K, Ichikawa S, et al. Lifestyle and the development of hypertension: a 3-year followup study of middle-aged Japanese male office workers. Occup Med I999; 49: I09-II4.

50. Kageyama T, Nishikido N, Kobayashi T, Kawagoe H. Estimated sleep debt and work stress in Japanese white-collar workers. Psychiatr Clin Neurosci 200I; 55:217-2I9.

5I. Kageyama T, Nishikido N, Kobayashi T, et al. Long commuting time, extensive overtime, and sympathodominant state assessed in terms of short-term heart rate variability among male white-collar workers in the Tokyo megalopolis. Ind Health 1998; 36: 209-217.

52. Iwasaki K, Sasaki T, Oka T, Hisanaga N. Effect of working hours on biological functions related to cardiovascular system among salesmen in a machinery manufacturing company. Ind Health I998; 36: 36I-367.

53. Proctor SP, White RF, Robins TG, et al. Effect of overtime work on cognitive function in automotive workers. Scand J Work Environ Health I996; 22: I24-I32.

54. Wagstaff AS, Sigstad Lie J-A. Shift and night work and long working hours? A systematic review of safety implications. Scand J Work Environ Health 20II; 37(3): I73-I85, doi:I0.527I/sjweh.3I46.

55. Smith MJ, Colligan MJ. Health and safety conse- quences of shift work in the food-processing industry. Ergonomics I982; 25: I33-I 44.

56. Gold DR, Rogacz S, Bock N, et al. Rotating shift work, sleep, and accidents related to sleepiness in hospital nurses. Am J Public Health I992; 82: IOI I-IOI4.

57. Hanecke K, Tiedemann S, Nachreiner F, GrzechSukalo H. Accident risk as a function of hour at work and time of day as determined from accident data and exposure models for the German working population. Scand J Work Environ Health I998; 24 Suppl 3: 43-48.

58. Gander PH, Merry A, Millar MM, Weller J. Hours of work and fatigue-related error: a survey of New Zealand anaesthetists. Anaesth Intensive Care 2000; 28: I78-I83.

59. Landrigan CP, Rothschild JM, Cronin JW, et al. Effect of reducing interns' work hours on serious medical errors in intensive care units. N Engl J Med 2004; 35I: I838-I 848 .

6o. Rogers AE, Hwang WT, Scott LD, et al. The working hours of hospital staff nurses and patient safety. Health Affairs 2004; 23: 202-2I 2.

6I. Garbarino S, Mascialino B, Penco MA, et al. Professional shift-work drivers who adopt prophylactic naps can reduce the risk of car accidents during night work. Sleep 2004; 27: I 295-I302.

62. Barger LK, Cade BE, Ayas NT, et al. Extended work shifts and the risk of motor vehicle crashes among interns. N Engl J Med 2005; 352: I 25-I34.

63. Dong X. Long workhours, work scheduling and workrelated injuries among construction workers in the United States. Scand J Work Environ Health 2005; 3I: 329-335.

64. Dembe AE, Erickson JB, Delbos RG, Banks SM. The impact of overtime and long work hours on occupational injuries and illnesses: new evidence from the United States. Occup Environ Med 2005; 62: 588-597.

65. Dembe AE, Erickson JB, Delbos RG, Banks SM. Nonstandard shift schedules and the risk of job-related injuries. Scand J Work Environ Health 2006; 32: 232-240.

66. Hanowski RJ. The sleep of commercial vehicle drivers under the 2003 hours-of-service regulations. Accid Anal Prev 2007; 4I: 268-275.

67. Fransen M, Wilsmore B, Winstanley J, et al. Shift work and work injury in the New Zealand Blood Donors' Health Study. Occup Environ Med 2006; 63: 352-358.

68. Vegso S, Cantley L, Slade M, et al. Extended work hours and risk of acute occupational injury: A casecrossover study of workers in manufacturing. Am J Ind Med 2007; 50: 597-603.

69. Goudswaard A, Kwantes JH. Arbeids- en rusttijden. Arbo-informatie 2006; 38.

70. Knauth P, Hornberger, S. Preventive and compensatory measures for shift workers. Occup Med 2003; 53: I09-II6.

7I. Leede J de, Dalen EJ van. Zelfroosteren past in vele trends. Gids voor Personeelsmanagement 2009; 88(4): 42-45. 